\title{
Fathers' Feelings and Experience Related to their Wife/Partner's Delivery in Northern Greece
}

\author{
Despina Sapountzi-Krepia ${ }^{*}, 1,2$, Maria Lavdaniti ${ }^{1}$, Alexandra Dimitriadou ${ }^{1}$, Maria Psychogiou ${ }^{2}$, \\ Markos Sgantzos ${ }^{3}$, Hong-Gu He ${ }^{4}$, Eythimios Faros ${ }^{5}$ and Katri Vehviläinen-Julkunen ${ }^{2}$
}

\author{
${ }^{I}$ Department of Nursing, Alexander Technological Educational Institute of Thessaloniki, Greece \\ ${ }^{2}$ Department of Nursing Science, University of Kuopio, Finland \\ ${ }^{3}$ Department of Medicine, University of Thessaly, Larissa, Greece \\ ${ }^{4}$ Alice Lee Center for Nursing Studies, National University of Singapore, Singapore \\ ${ }^{5}$ Private Practice, Athens, Greece
}

\begin{abstract}
Objectives: The study aims at exploring the feelings and the experience of fathers about their wife/partner's delivery.

Background: During the last decades birth attendance by fathers is a common phenomenon across many countries. Fathers' birth attendance may evoke both positive and negative feelings.

Methodology: The study was conducted in a city of Northern Greece. The sample consisted of 417 fathers whose wife/partner had given birth during the previous one week to one year. Data were collected using the Kuopio Instrument for Fathers (KIF).

Results: Father's feelings about their wife or partner were very positive as nearly all $(82.1 \%)$ of the participants were proud to become fathers and agree that they felt love and were grateful to their wife/partner. However, half of the fathers felt anxious and nervous. $40.7 \%$ quite agree that the staff was very professional, that they trusted the staff (45\%) and that they were grateful to the staff $(38.8 \%)$. There is correlation between the "feelings related to the wife/partner" and education $(\mathrm{r}=0.156, \mathrm{p}=0.0047)$, "being afraid during the preparatory visit at the obstetric hospital" $(\mathrm{r}=-0.238, \mathrm{p}=0.009)$, and "anxiety during the preparatory visit" $(\mathrm{r}=0.295 \mathrm{p}=0.005)$. The subscale "feelings related to the environment and staff" correlates with "usefulness of preparatory visit" $(\mathrm{r}=-0.223, \mathrm{p}=0.004)$ and the subscale of "experiences related to delivery" correlates with "usefulness of preparatory visit" $(\mathrm{r}=-0.357, \mathrm{p}=0.001)$.
\end{abstract}

Conclusions: Our results support the findings of previous studies, which indicated that birth attendance by fathers has evoked positive feelings about their wife/partner, the delivery, the staff and the hospital environment.

Keywords: Fathers, delivery, feelings, experiences, Greece, birth attendance, survey.

\section{INTRODUCTION}

During the last decades there was an expansion of the fathers' role in the family [1]. Men's attendance at the delivery has increased, mainly in Western industrial countries [2-7]. According to Somers-Smith [4], about 95\% of fathers in England attend the delivery of their baby. In Scandinavian countries there is a similar situation. The World Health Organization [8] stated that in Denmark 95\% of fathers attend the delivery, and in Finland hospitals have been allowing father to attend the delivery since the $1960 \mathrm{~s}$ [6]. Recently, the father's attendance at the delivery is reported also in developing countries $[9,10]$ and in lower income countries [8].

*Address correspondence to this author at the Nursing Department, Alexander Technological Educational Institute of Thessaloniki, PO Box 1456, TK 541 01, Thessaloniki, Greece; Te1/Fax: 0030 2310791501;

E-mail: desapoun@yahoo.com
In Greece, fathers' birth attendance traditionally has not been very popular. In 1992, Dragonas found that only $10 \%$ of fathers were present at the delivery and the main reason for non-attendance was hospital policy or the father's/mother's decision [11]. There is no more recent information, from either research or official records, on Greek fathers' birth attendance. However, private hospitals in Greece have developed new policies and are allowing fathers to be present during childbirth, while public hospitals still restrict the fathers' presence in the delivery room.

There are several studies examining the fathers' experience of attending the birth of their child [5, 7, 11-16]. Fathers reported that labour experience evoked generally positive feelings $[6,12,15]$, as well as a significant number of negative responses [12]. Some fathers feel it is very difficult to see their partner in pain $[5,6,14,16]$. It is reported that the best experience for fathers was the moment when the baby entered the world $[6,17]$ and that fathers' birth attendance has resulted in a closer emotional bond with 
the newborn [11]. We could say that the fathers' participation in the process of childbirth, helps towards the father's involvement in raising their children [9] and contributes to their growth into fatherhood $[6,17]$.

Some fathers found childbirth to be a stressful experience $[4,18,19]$. Somers-Smith stated that fathers were uncertain about their supporting role, the well being of their partner and any complications that might occur to the mother or to the baby [4]. A qualitative study found that fathers were confident of their ability to support their wives, but they became fearful for their babies at the time of birth [18]. In another study, it was reported that the stress caused by childbirth may have an impact on father/child bonding [19]. Some men reported that they feel stressed by the demands on them to be an active birth coach and they have doubts about their contribution to the delivery [20]. In addition, it has been stated that fathers feelings are not sufficiently prepared due to the predominant role of the mother, as well as the lack of support and instruction during birth [14].

Many research findings demonstrate that support from partners has positive effects during birth [21, 22]. It was found that support from spouses helped mothers to have more positive experiences during childbirth [22], and mothers value positively their presence [21]. Also, it was found that partners' support was positively related to the dosage of pain-relieving drugs used and the total length of labour [23]. Therefore, Somers-Smith stated that women welcome the support provided by the fathers [4].

Other studies focused on the role of fathers during delivery. Chapman showed that when men were present during birth, they were co-laboring in one of three roles: coach, teammate or witness [20]. Somers-Smith found that most fathers defined their role in terms of general support during delivery [4].

It has been supported that fathers' emotions differ according to the type of delivery. They find caesarean delivery more traumatic and express more anxiety than in vaginal delivery $[7,15]$.

Although the body of evidence regarding fathers' experiences and feelings about delivery is growing over the world, the existing literature in Greece is mainly focused on maternity services [24], on family dynamics during pregnancy [25], instrument validation in the Greek population [26, 27], and emotions about childbirth [28]. To our knowledge there is no prior Greek study in relation to fathers' experience and feelings, so we decided to investigate this topic in Northern Greece through a broad survey.

\section{OBJECTIVES}

The objectives of the present study were to assess fathers' feelings and the experience about their wife/partner's delivery. The research questions were the following:

1. What kind of feelings and experiences do fathers have during delivery?

2. What kind of correlations are there between fathers' feelings and experiences and other variables (e.g. presence during delivery, preparatory visit, safeness of obstetric hospital)?

\section{METHODOLOGY}

\section{Setting and Sample}

The study was descriptive in design. The sample consisted of 417 fathers whose wife or partner had given birth during the previous one week to one year. The participants were living in the greater area of Thessaloniki city, as well as in six cities located in the vicinity of Thessaloniki. Inclusion criteria were: a) to be at least 18 years old, b) ability to speak and read Greek, and c) willingness to participate.

\section{Data Collection}

Potential participants were recruited from the community. The researchers first approached some fathers through hospital maternity clinics. Then we used the snowball technique to recruit more participants, by having participant fathers introducing us to other fathers from their social environment.

All potential participants were approached by a member of the research team and were explained the purpose of the study. They were given information about the study, including confidentiality issues, and they had the opportunity to ask questions. Informed consent forms were collected from those who agreed to participate; afterwards they were given the questionnaire to complete.

\section{Ethical Issues}

The Administrative Scientific Committee of the Nursing Department of the Alexander Technological Educational Institution of Thessaloniki, acting as an ethics committee, granted Ethical approval for the study protocol.

\section{Instrument}

We used the Kuopio Instrument for Fathers (KIF); a questionnaire especially designed to explore fathers' feelings and experiences related to their wife/partner's delivery. The testretest reliability of the KIF questionnaire was assessed in the Greek population and was found to be satisfactory [26].

The first part of the KIF questionnaire contains questions about the demographic and social characteristics of the participants. The second part of the KIF questionnaire contains two scales. The first scale is a 35 -item scale for eliciting information on the father's feelings related to his wife/partner's delivery. This scale is divided into four subscales: a) a 13-item subscale for eliciting information on father's own feelings, $b$ ) a 7-item subscale on father's feelings concerning his wife/partner, c) a 5-item subscale on father's feelings about the birth of his child, and d) a 10-item subscale on father's feelings about the hospital staff and environment. The second scale is a 19-item scale for eliciting information from fathers who were present in the delivery room regarding their experiences related to their wife/partner's delivery.

Both scales are scored using a five-point Likert scale (totally agree, agree to some extent, difficult to say, disagree to some extent, totally disagree). In the present study, Cronbach's alpha of the scale ranged from 0.61 to 0.90 .

\section{Data Analysis}

The data were analysed using SPSS version 13.0. Responses to items on the questionnaires were coded and then entered into SPSS. Verification of the data was done using double data entry. Descriptive statistics were used to 
analyze demographic characteristics and for frequencies of items of the KIF questionnaire. For data that were not normally distributed non-parametric tests were used (Spearman correlation coefficient). Correlations were calculated using the Spearman correlation coefficient and significance was set to $5 \%$.

\section{RESULTS}

The mean age of the participant fathers was $36.24 \pm 6.85$ years. Seventy seven point one percent $(n=319)$ of the respondents had completed secondary education (lyceum), nearly all $95.2 \%$ were married and $97.9 \%$ employed. The sample's demographic and social characteristics are presented in Table $\mathbf{1 .}$

Table 1. Demographic Characteristics of the Sample

\begin{tabular}{|c|c|c|}
\hline & $\mathbf{N}$ & $\%$ \\
\hline \multicolumn{3}{|l|}{ Marital Status } \\
\hline Married & 400 & 95.2 \\
\hline Cohabiting & 10 & 2.6 \\
\hline Unmarried & 7 & 1.7 \\
\hline \multicolumn{3}{|l|}{ Education } \\
\hline Primary school & 27 & 6.5 \\
\hline Secondary school (gymnasium) & 68 & 16.4 \\
\hline Secondary school (lyceum) & 319 & 77.1 \\
\hline \multicolumn{3}{|l|}{ Occupational Education } \\
\hline No occupational course & 69 & 17.5 \\
\hline Occupational course & 97 & 24.6 \\
\hline Post-secondary occupational diploma & 22 & 5.6 \\
\hline College-level occupational diploma & 31 & 7.8 \\
\hline Academic degree & 141 & 35.7 \\
\hline Other & 35 & 8.9 \\
\hline \multicolumn{3}{|l|}{ Employment } \\
\hline Employed & 410 & 97.9 \\
\hline Unemployed & 3 & 0.7 \\
\hline Other & 4 & 1.4 \\
\hline
\end{tabular}

Forty seven point four percent $(n=199)$ were first time fathers, $37.4 \%$ were second time fathers, and the remaining $15.2 \%$ became fathers for at least the third time. Regarding the mode of delivery, $34.7 \%(n=145)$ of participants reported that the delivery was performed by caesarean section, while $65.3 \%(n=273)$ were vaginal deliveries. Sixty six percent $(n=257)$ consider being present at the delivery "extremely important" or "important to some extent", $8.3 \%$ did not think it was important, while $25.7 \%$ found it difficult to give an answer. Nevertheless, over half $(54,3 \%)$ of the fathers were in the delivery room during their wife/partner's labor and delivery; for $61.8 \%$ of them this was the wish of both partners. About half of fathers had a preparatory visit at the obstetric hospital. Among them, 41.9\% found the preparatory visit "useful to some extent" or "very useful", while nearly one third $(29.3 \%)$ said that this visit frightened them. Forty one point six percent $(n=175)$ considered the obstetric hospital to be a safe place for giving birth.

Table 2 presents the frequencies of the fathers' feelings related to wife/partner's delivery. Fathers' own feelings and feelings about his wife or partner were mainly positive as $82.1 \%$ of the participants said they were proud to become a father, while $40 \%$ were nervous and $51 \%$ were anxious. The majority of the fathers $(82.4 \%)$ felt love for their wife/partner, while a considerable percentage (65.2\%) was grateful to their wife/partner. Fathers' feelings about the birth of his child were on positive side as $86.2 \%$ were proud of the baby, $90.2 \%$ were happy about the baby. However, over half $(57.3 \%)$ were worried about the health of the baby. Forty point seven percent $(n=171)$ of the participants "agreed to some extent" that the staff were very professional, $45 \%$ "agreed to some extent" that they trusted the staff, and $38.8 \%$ were grateful to the staff. In addition, $63.8 \%$ trusted the safety of the delivery environment.

Table 3 shows the frequencies of the experiences of the fathers who were present in the delivery room during their wife/partner delivery. Only 228 participant fathers were present during delivery and completed the subscale about the experiences related to the wife/partner's delivery. Fifteen point seven percent $(n=66)$ "totally agreed" that they were encouraged to express their feelings and $16.7 \%$ "totally agreed" that they were encouranged to be themselves. Nineteen point eight percent $(n=83)$ "totally disagreed" that they were told to take care of their physical health and every third $(32.4 \%)$ informed that attention was given to their psychological wellbeing. Thirty one point four percent $(n=132)$ said that they were told about the progress of the delivery. Furthermore, $26.4 \%$ of the fathers agreed that they were encouraged to be present when the baby was taken to the mother's breast and 32.9\% "totally agreed" that they were encouraged to touch the baby. However, only one fifth informed that they were encouraged to bathe the baby.

Table 4 shows the correlations between the subscales and the variables from the fathers' basic information. The subscale of "feeling related to the delivery" correlates with the variables "presence during delivery" $(\mathrm{r}=-0.222, \mathrm{p}=0.000)$, "presence during past delivery" $(\mathrm{r}=-0.018, \mathrm{p}=0.033)$, "being frightened at preparatory visit to the obstetric hospital" $(\mathrm{r}=0.187 \mathrm{p}=0.009)$, and "anxiety at preparatory visit" $(\mathrm{r}=0.192, \mathrm{p}=0.007)$. Also, the subscale of "feelings related to the wife/partner" correlates significantly with education $(\mathrm{r}=0.156, \mathrm{p}=0.0047)$, with "being frightened at preparatory visit to the obstetric hospital" $(r=-0.238, \mathrm{p}=0.009)$ and with "anxiety at preparatory visit" $(\mathrm{r}=0.295, \mathrm{p}=0.005)$. The subscale "feelings related to delivery" correlates only with "a safe place to give birth" $(\mathrm{r}=-0.1127, \mathrm{p}=0.048)$. The subscale "feelings related to the environment and staff" correlates with "presence during delivery" $(\mathrm{r}=0.186, \mathrm{p}=0.014)$, "presence during past delivery" $(\mathrm{r}=-0.128, \mathrm{p}=0.014)$, "previous visit to the obstetric hospital" ( $\mathrm{r}=-0.222, \mathrm{p}=0.003)$, "usefulness of preparatory visit" $(\mathrm{r}=-0.223, \mathrm{p}=0.004)$, and the "safety of the obstetric hospital" ( $r=-0.378, \mathrm{p}=0.000)$. 
Table 2. Fathers' Feelings and Experiences During Delivery

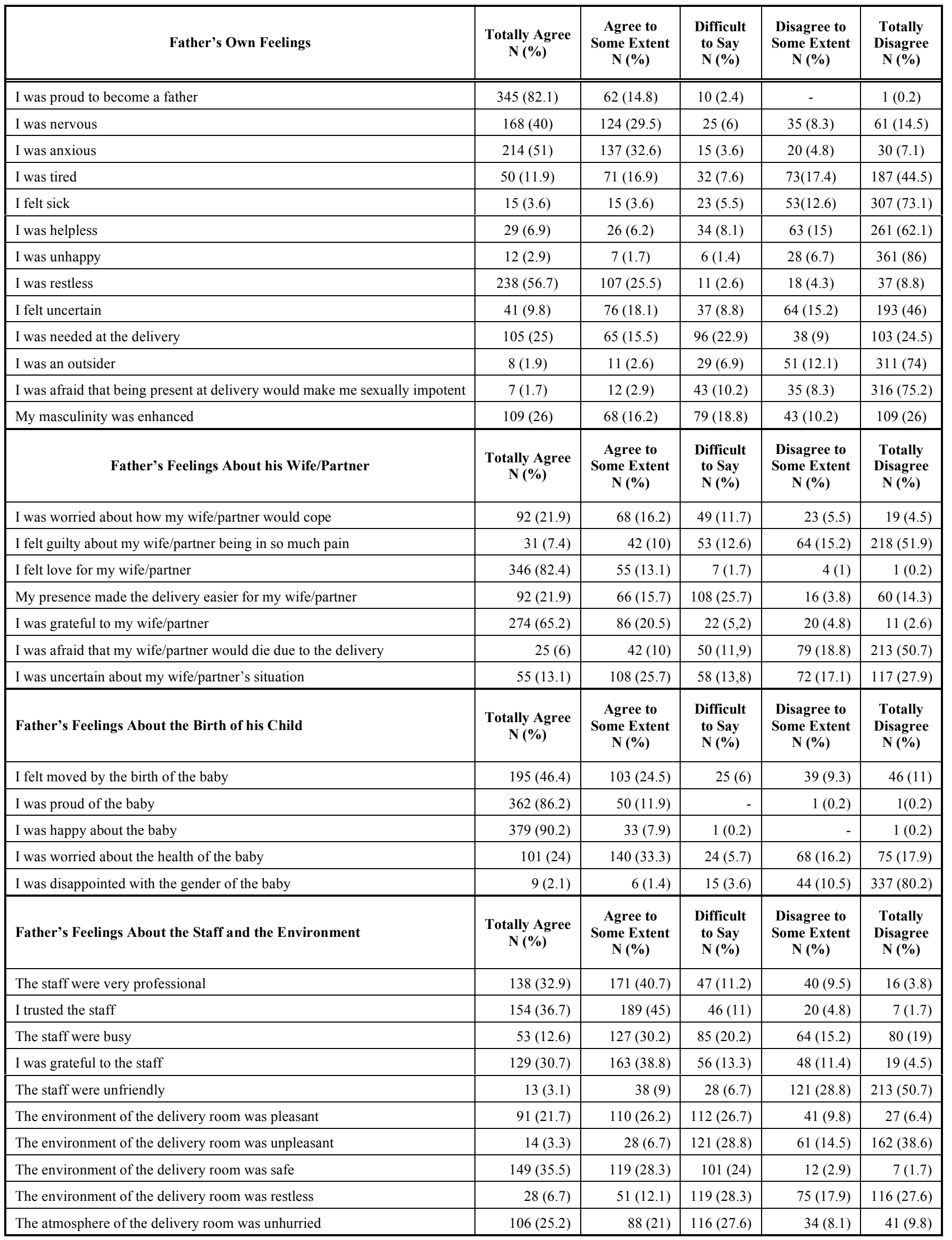


Table 3. Experiences of Fathers who were Present During Delivery Related to their Wife/Partner's Delivery (n=228)

\begin{tabular}{|c|c|c|c|c|c|}
\hline & $\begin{array}{l}\text { Totally Agree } \\
\quad \text { N (\%) }\end{array}$ & $\begin{array}{c}\text { Agree to } \\
\text { Some Extent } \\
\text { N (\%) }\end{array}$ & $\begin{array}{l}\text { Difficult } \\
\text { to Say } \\
\text { N (\%) }\end{array}$ & $\begin{array}{c}\text { Disagree to } \\
\text { Some Extent } \\
\text { N (\%) }\end{array}$ & $\begin{array}{c}\text { Totally } \\
\text { Disagree } \\
\text { N (\%) }\end{array}$ \\
\hline I was encouraged to express my feelings & $66(15.7)$ & $63(15)$ & $29(6.9)$ & $39(9.3)$ & $31(54.3)$ \\
\hline I was encouraged to be myself & $70(16.7)$ & $54(12.9)$ & $35(8.3)$ & $35(8.3)$ & $32(7.6)$ \\
\hline I was told to take care of my physical health & $36(8.6)$ & $31(7.4)$ & $41(9.8)$ & $33(7.9)$ & $83(19.8)$ \\
\hline Attention was given to my psychological wellbeing & $68(16.2)$ & $68(16.2)$ & $24(5.7)$ & $38(9)$ & $27(6.4)$ \\
\hline I was not treated like an outsider & $114(27.1)$ & $72(17.1)$ & $10(2.4)$ & $10(2.4)$ & $17(4)$ \\
\hline I was told about the progress of the delivery & $132(31.4)$ & $57(13.6)$ & $4(1)$ & $25(6)$ & $7(1.7)$ \\
\hline The staff discussed the progress of the delivery with me & $108(25.7)$ & $55(13.1)$ & $14(3.3)$ & $28(6.7)$ & $22(5.2)$ \\
\hline The staff discussed the welfare of the baby with me & $110(26.2)$ & $57(13.6)$ & $8(1.9)$ & $22(5.2)$ & $18(4.3)$ \\
\hline The staff discussed with me the characteristics of my newborn baby & $74(17.6)$ & $58(13.8)$ & $30(7.1)$ & $29(6.9)$ & $36(8.6)$ \\
\hline $\begin{array}{l}\text { I was encouraged to be present when the } \\
\text { baby was first taken to the mother's breast }\end{array}$ & $111(26.4)$ & $47(11.2)$ & $10(2.4)$ & $18(4.3)$ & $38(9)$ \\
\hline I was encouraged to touch the newborn baby & $138(32.9)$ & $44(10.5)$ & $9(2.1)$ & $10(2.4)$ & $24(5.7)$ \\
\hline I was encouraged to participate in measuring and weighing the baby & $72(17.1)$ & $31(7.4)$ & $17(4)$ & $33(7.9)$ & $72(17.1)$ \\
\hline I was encouraged to bathe the baby & $61(14.5)$ & $27(6.4)$ & $20(4.8)$ & $37(8.8)$ & $78(18.6)$ \\
\hline I was shown how to bathe the baby & $65(15.5)$ & $39(9.3)$ & $12(2.9)$ & $24(5.7)$ & $83(19.8)$ \\
\hline I was encouraged to hold the baby & $123(29.3)$ & $51(12.1)$ & $4(1)$ & $7(1.7)$ & $41(9.8)$ \\
\hline
\end{tabular}

\section{DISCUSSION}

The study assessed the fathers' feelings and experiences about their wife/partner's delivery thru a broad survey. It contributes to the growing body of evidence regarding fathers' feelings about delivery and provides an important foundation for Greek nurses and midwives, because describing this phenomenon is vital for planning appropriate interventions.

Almost half of the fathers were present at the delivery and this was the wish of both partners. This is consistent with findings from other countries where approximately half of the fathers were present at the delivery, but they reported that they were pressured by their wives [29]. On the other hand, this finding differs from a Finnish study in which almost all fathers were present at the delivery after the request of, or in agreement with their partners [6].

The findings indicate that, during delivery, fathers had negative feelings, such as nervousness, anxiety and restlessness, as well as also positive feelings, such as feeling proud and happy. This is consistent with other studies $[6,12$, 15, 18]. Bradley et al. examined 199 men attending their partner's labour and delivery, and concluded that the feeling most commonly reported was anxiety [30]. Our result supports Draper who stated that there are benefits, as well as disadvantages, for men attending birth [3]. However, both partners should discuss it and make the decision which is right for them $[3,31]$.

Most of the participants attending the delivery did not feel guilty about their wife/partner being in so much pain. Other studies reported that fathers felt it was very difficult to see their partner in pain [5]; for them it was the most unpleasant and difficult thing [6] and witnessing their partner in pain was the worst aspect of having a child [16]. Also, Hallgren et al. reported that fathers felt unprepared for the experience of time and pain. There is a need for future research in the Greek population to examine this issue [14].

The participant fathers have positive feelings for their partner/wife, such as love and gratefulness. This finding is an indicator that the relationship between the couple is strengthened. This is similar to findings from previous studies $[6,11,15]$. Dragonas reported that Greek fathers who were present during childbirth reported that their attendance resulted in a closer emotional bond with their partner [11]. Chan \& Paterson-Brown found that labour experience improves the relationship between partners [15]. In another study men expressed an enhanced respect for their wives [18]. In a study by Vehvilainen-Julkunen \& Liukkonen fathers said that they feel gratefulness and love for their partner [6]. Fagerskiold stated that "during the delivery, fathers often realised how capable their partner was and this led to an increased admiration for her" [32].

It is important to note that the majority of the participants have pleasant or positive feelings for their baby, such as being proud and happy. This is an expected outcome since similar results reported in earlier studies stressed being proud and happy about the baby [6], love [17], and being very interested in the baby at the time of birth [18], as well as a closer emotional bond with the newborn [11].

The respondents expressed quite positive thoughts about the staff and the environment, and stated that the work of the staff was reliable and the environment was pleasant, safe and unhurried. This is consistent with the study of VehvilainenJulkunen.\& Liukkonen which found that the work of midwives was reliable and professional, the environment was considered as quiet and comfortable, and the atmosphere 
Table 4. Correlations Between KIF Subscales and Basic Information

\begin{tabular}{|c|c|c|c|c|c|c|c|c|}
\hline \multirow[t]{2}{*}{ Variables } & \multicolumn{2}{|c|}{$\begin{array}{l}\text { Father's Own } \\
\text { Feelings During } \\
\text { Delivery }\end{array}$} & \multicolumn{2}{|c|}{$\begin{array}{c}\text { Father's Feelings } \\
\text { About his } \\
\text { Wife/Partner }\end{array}$} & \multicolumn{2}{|c|}{$\begin{array}{l}\text { Father's Feelings } \\
\text { About the Birth } \\
\text { of his Child }\end{array}$} & \multicolumn{2}{|c|}{$\begin{array}{l}\text { Father's Feelings } \\
\text { About the Staff \& } \\
\text { the Environment }\end{array}$} \\
\hline & $\mathbf{r}$ & $\mathbf{p}$ & $\mathbf{r}$ & $\mathbf{p}$ & $\mathbf{r}$ & $\mathbf{p}$ & $\mathbf{r}$ & $\mathbf{p}$ \\
\hline Basic Education & NS & NS & 0.156 & 0.047 & NS & NS & NS & NS \\
\hline Employment & NS & NS & NS & NS & NS & NS & NS & NS \\
\hline How significant is the presence during delivery? & -0.222 & 0.000 & NS & NS & NS & NS & 0.186 & 0.000 \\
\hline Were you present during past delivery? & -0.018 & 0.033 & NS & NS & NS & NS & -0.128 & 0.014 \\
\hline $\begin{array}{l}\text { Did you visit the obstetric hospital } \\
\text { before your wife/partner gave birth? }\end{array}$ & NS & NS & NS & NS & NS & NS & -0.222 & 0.003 \\
\hline $\begin{array}{l}\text { Do you consider that a preparatory visit } \\
\text { to the obstetric hospital is useful? }\end{array}$ & NS & NS & NS & NS & NS & NS & -0.223 & 0.004 \\
\hline Did the preparatory visit frighten you? & 0.187 & 0.009 & -0.238 & 0.009 & NS & NS & NS & NS \\
\hline Did the preparatory visit cause you anxiety? & 0.192 & 0.007 & 0.295 & 0.005 & NS & NS & NS & NS \\
\hline How safe for the delivery is this obstetric hospital? & NS & NS & NS & NS & -0.113 & 0.0048 & -0.378 & 0.000 \\
\hline
\end{tabular}

was unhurried [6]. However, this result is not supported by the study of Wikander \& Theorell which found that staff behaviour was considered negative more commonly by the group of fathers who experienced the delivery as a negative event [33].

As for the experiences related to their wife/partner's delivery, the majority of fathers had positive thoughts about getting information about the delivery, attention for themselves and for infant care. This finding is consistent with studies reporting that fathers felt they got encouragement for their feelings, information about infant care [5], felt that midwives explain things to help them understand clinical procedures, baby behaviour and partner's needs [34]. Considering these points, we believe it is obvious that fathers are not simply observers, but have a significant role during delivery.

Other studies investigating fathers' experience of childbirth $[14,18]$ concluded that either the midwives should design childbirth preparation from the men's perspective, discuss expectations with regard to the men's role, and assess their experiences during the birth process [14], or that fathers need to be encouraged to eat and take a break from the labour when appropriate [18]. In an earlier study, fathers felt excluded from the child bearing experience by their partners and health providers [35]. Therefore, we agree with Draper's statement "the lack of support some receive from the professionals reflects views held by society as a whole" [3].

In this study we were also interested in examining the effect of the father's feelings and experiences during the preparatory visit at the obstetric hospital on their presence at delivery. There are correlations among subscales of the KIF questionnaire and being frighten, feeling anxiety, usefulness of preparatory visit, and the safety of the obstetric hospital (there are negative correlations between being frighten and feelings on environment and experiences related to delivery). These correlations suggest that the feelings and experiences of fathers attending the delivery were affected by the preparatory visit at the obstetric hospital. This finding can lead us to the conclusion that Greek fathers need education and preparation (antenatal education) before delivery. This is consistent with Nolan's assessment of men's experiences of antenatal education; it indicates that men want more information during pregnancy in order to attend birth [36]. Since, in Greece, there aren't earlier studies on preparatory visits, we propose conducting future research to examine this issue.

Finally, correlations between education and "feelings related to the wife/partner" and between "occupation and experiences" suggest that the type of education and employment affect the father's feelings and experiences. This is consistent with another Greek study which explored the reaction to fatherhood and found that manual laborers and fathers with primary education tended to react negatively to fatherhood [11].

\section{LIMITATIONS OF THE STUDY}

There are some limitations, which should be discussed. A survey methodology was used in data collection. A sampling bias may have been introduced since we did not use random sampling. Due to recent legislation about personal data protection, random sampling was not possible since patient names and addresses can no longer be released to the researchers. Therefore, we used the snowball recruitment technique. Nevertheless, snowball recruitment has been used as a sampling method since the 1960 s and has proven to be very useful in healthcare studies [37]. Another possible limitation of this study is the representativeness of the results. Only a few cities in Northern Greece were represented, although Thessaloniki is the largest city in northern Greece and the second largest city of the country. Since this is the first Greek study on the topic, we believe that the results are worth sharing with the research community.

\section{CONCLUSIONS}

The findings of this study revealed that the majority of fathers experienced feelings of discomfort at the delivery (anxiety, nervousness, restlessness). The nursing staff should 
provide reliable information related to delivery, as well as education before childbirth, and should also encourage fathers during delivery. In this way the discomfort will be minimized [6]. Furthermore, the fathers' preparation for their role, the provision of information about the basics of baby care (e.g. bathing, breastfeeding), and how to handle the baby at home, is another aspect that can be covered by the staff in the obstetric hospital.

Although fathers are quite satisfied by the staff's encouragement during delivery, there is a need for further support for the fathers during delivery in order for them to respond to their role in the delivery room.

There is a need for further research to examine the fathers' experiences and feelings during different mode of delivery (vaginal or caesarean section) with qualitative research methods. Finally, further research examining the description of feelings and experiences of fatherhood could add to the Greek nursing literature.

\section{ACKNOWLEDGEMENT}

The present study has been funded by the Academy of Finland, grant no. 13522, decision 106333.

\section{REFERENCES}

[1] Garfield CF, Isacco A. Fathers and well-child-visit. Pediatrics 2006; 117: 637-45.

[2] David M, Reich A, Morack G, Kentenich H. Fathers in the delivery-room: an East/West comparison (in German). Z Geburtshilfe Perinatology 1994; 198(4): 138-42.

[3] Draper J. Whose welfare in the labour room? A discussion of the increasing trend of fathers' birth attendance. Midwifery 1997; 13(3): 132-8.

[4] Somers-Smith MJ. Place for the partner? Expectations and experiences of support during childbirth. Midwifery 1999; 15(2): 101-8.

[5] Liukkonen A, Vehvilainen-Julkunen K. Fathers' childbirth experience and nursing interventions. Hoitotiede 1997; 9(3): 11826.

[6] Vehvilainen-Julkunen K, Liukkonen A. Fathers' experiences of childbirth. Midwifery 1998; 14(1):10-7.

[7] Greenhalgh R, Slade P, Spiby H. Fathers' coping style, antenatal preparation, and experiences of labor and the postpartum. Birth 2000; 27(3): 177-84.

[8] World Health Organization. Fatherhood and Health outcomes in Europe. 2007; Available at http://www.euro.who.int/document/e91129.pdf (Accessed March 4th 2009).

[9] de Carvalho ML. Fathers' participation in childbirth at a public hospital: institutional difficulties and motivations of couples (in Portuguese). Cadenos de Saude Publica 2003; 19(Suppl 2): S38998.

[10] Carter MW, Speizer I. Salvadoran fathers' attendance at prenatal care, delivery, and postpartum care. Rev Panam Salud Publica 2005; 18(3): 149-56.

[11] Dragonas TG. Greek fathers' participation in labour and care of the infant. Scand J Caring Sci 1992; 6(3):151-9.

[12] Nichols MR. Paternal perspectives of the childbirth experience. Matern Child Nurs J 1993; 21(3): 99-108.

[13] Barclay L, Donovan J, Genovese A. Men's experiences during their partner's first pregnancy: a grounded theory analysis. Aust J Adv Nurs 1996; 13(3): 12-24.
[14] Hallgren A, Kihlgren M, Forslin L, Norberg A. Swedish fathers' involvement in and experiences of childbirth preparation and childbirth. Midwifery 1999; 15(1): 6-15.

[15] Chan KK, Paterson-Brown S. How do fathers feel after accompanying their partners in labour and delivery? J Obstet Gynaecol 2002; 22(1): 11-5.

[16] Capogna G, Camorcia M, Stirparo S. Expectant fathers experience during labor with or without epidural analgesia. Int J Obstet Anesth 2007; 16(2): 110-5.

[17] Hall EO. From fun and excitement to joy and trouble - An explorative study of three Danish fathers' experiences around birth. Scand J Caring Sci 1995; 9(3): 171-9.

[18] Chandler S, Field PA. Becoming a father. First-time fathers' experience of labor and delivery. J Nurse Midwifery 1997; 42(1): 17-24.

[19] Johnson MP. The implications of unfulfilled expectations and perceived pressure to attend the birth on men's stress levels following birth attendance: A longitudinal study. J Psychosom Obstet Gynaecol 2002; 23(3): 173-82.

[20] Chapman L. Searching: Expectant father's experiences during labour and birth. J Perinat Neonatal Nurs 1991; 4(4): 21-9.

[21] Chamlers B, Wolman W. Social support in labor. J Psychosom Obstet Gynaecol 1993; 14(1): 1-15.

[22] Gugnor I, Beji NK. Effects of fathers' attendance to labor and delivery on the experience of childbirth in Turkey. West J Nurs Res 2007; 29(2): 213-31.

[23] Ip WY. Relationships between partners support during labour and maternal outcomes. J Clin Nurs 2000; 9(2): 265-72.

[24] Sapountzi-Krepia D, Vehvilainen-Julkunen K. Maternity care in Greece. Nosileftiki 2006; 45: 160-8 (English abstract).

[25] Likeridou K, Hyrkäs K, Paunonen M, Lehti K. Family dynamics of child-bearing families in Athens, Greece: A pilot study. Int J Nurs Pract 2001; 7(1): 30-7.

[26] Sapountzi-Krepia D, Raftopoulos V, Psychogiou M, Tzavelas G, Vehvilainen-Julkunen K. Test-retest reliability of the Kuopio instrument for fathers (KIF): a questionnaire to assess fathers' feelings, experiences and preparation for their wife/partner's delivery. Midwifery 2009; 25(4): 366-72.

[27] Sapountzi-Krepia D, Raftopoulos V, Tzavelas G, Psychogiou M, Callister LC, Vehvilainen-Julkunen K. Mothers' experiences of maternity services: internal consistency and test-retest reliability of the Greek translation of the Kuopio Instrument for Mothers. Midwifery 2009; 25(6): 691-700.

[28] Moraitou M, Lykeridou A. Childbirth scene evaluation for the growth of positive emotions. Nosileftiki 2007; 46(4): 453-9.

[29] Palkovitz R. Changes in father-infant bonding beliefs across couples, first transition to parenthood. Matern Child Nurs J 1992; 20(3,4): 141-54.

[30] Bradley R, Slade P, Levistom A. Low rates of PSTD in men attending childbirth: A preliminary study. Br J Clin Psychol 2008; 47(Pt 3): 295-302.

[31] Niven C. How helpful is the presence of the husband at childbirth? J Reprod Infant Psychol 1985; 3: 45-53.

[32] Fagerskiold A. A view from inside the family-becoming. A change in life as experienced by first-time fathers. Scand J Caring Sci 2008; 22: 64-71.

[33] Wikander B, Theorell T. Father's experience of childbirth and its relation to crying in his infant. Scand J Caring Sci 1997; 11(3): 151-8.

[34] Sigh D, Newburn M. What men think of midwives. RCM Midwives 2003; 6(2): 70-74.

[35] Jordan PL. Laboring for relevance: expectant and new fatherhood. Nurs Res 1990; 39 (1): 11-6.

[36] Nolan M. Caring for fathers in antenatal classes. Modern Midwife 1994; 4(2): 25-8.

[37] Streeton R, Cooke M, Campbell J. Researching the researchers: using a snowball technique. Nurse Res 2004; 12: 35-46. 